\title{
TELENOVELA: INDUSTRIALIZAÇĀO DAS IMAGENS E DOS SONHOS
}

Antonio Chaves

Ex-Diretor da Faculdade de Direito da Universidade de São Paulo

\begin{abstract}
Resumo: A telenovela é uma mercadoria destinada a crescer extraordinariamente nos próximos anos. O seu consumo é calculado em cerca de dez milhões de horas em todo o mundo, noventa por cento dos quais em apenas seis nações: Estados Unidos, Itália, Canadá, Japão, Filipinas e Brasil. As duas maiores "fábricas" são, no mundo, a TV Globo e a Televisa Mexicana, todavia a TV Bandeirantes está exportando.
\end{abstract}

Riassunto: La telenovela é una merce destinata a crescere straordinariamente nei prossimi anni. Il suo consumo é calcolato in circa di dieci milioni di ore in tutto il mondo, $90 \%$ del quale da appena sei nazioni: Stati Uniti, Italia, Canadá, Giaponne, Filippine e Brasile. La due maggiori "fabbriche" sono, nel mondo, la TV Globo e la Televisa Messicana, ma anche la Rede Bandeirantes sta esportando.

Unitermos: Indústria cultural; Fome de imagens.

Encarnando um dos produtos típicos de cultura de massa, a telenovela, produto da industrialização das imagens, dos sonhos, do espírito, fez com que, como nunca antes, a vida privada entrasse no circuito comercial e industrial, nunca o "murmurar do mundo" tivesse sido, ao mesmo tempo, fabricado industrialmente e vendido comercialmente.

Com esse introito, inspirado em E. MORIN, L'industria culturale, Il Mulino, Bolonha, 1963, p. 9, dá início ANGELO ZACCONE TEODOSI à sua tese: A telenovela é uma mercadoria pobre que faz estremecer o mercado rico, apresentada à Reuniâo de Estudos: "A aldeia global: aquela parte do mundo denominada America Latina", organizada pelo "Teleconfronto, IV Exposição Internacional dos telefilmes", Chianciano Termas, 23 maio-1ำ junho 1986, enriquecida com elementos ulteriores e publicada em "Gulliver", mensário político sobre comunicações de massa, via Bertoloni, 44, Roma, n. 6 , junho 1986, pp. 20-33.

É uma contribuição do mais alto interesse, principalmente para o público brasileiro, não apenas pela riquíssima coleta de dados e bibliografia invocada, como ainda pela elegante exposição, revelando profundo conhecimento da situaçāo latinoamericana, especialmente brasileira. 
Começa realçando as dimensões quantitativas impressionantes de fenômeno: um imaginário arquivo-videoteca de telenovelas já conteria dezenas e dezenas de milhares de horas de programas.

A indagação se a telenovela fabrica e impōe, ou reflete as necessidades do público complica-se, demonstra desde logo, quando a mercadoria telenovela é submetida, como acontece na grande "fábrica" da TV Globo, no seu processo criativo-produtivo a cuidadosas pesquisas de mercado, que verificam continuamente sua correspondência por parte do conjunto dos consumidores, nāo-somente a nível de audiência, mas de avaliação quantitativa do agrado por parte do público que pode, pelo menos parcialmente, participar até mesmo no desenvolvimento da narração.

Ao nível de indústria audiovisiva, a telenovela é o produto que mais do que qualquer outro assume a roupagem de mercadoria, despindo-se do elegante manto de "unicidade" para apresentar como o seu maior "appeal" de marketing-mix justamente a circunstância da sua inexorável seriação, ao lado dos seus baixos (para os mercados internacionais) preço de venda e custo de produção.

Calcula o consumo de programas de TV em quantidade de horas em cerca de 10 milhōes por ano, a nível planetário, das quais 90\% são "consumidas" por apenas seis países: EUA, Itália, Canadá, Japão, Filipinas, Brasil.

Estimando a produção mensal de imagens no mundo inteiro que não passa de alguns milhares de horas, é fácil perceber a enorme diferença entre a procura e a oferta, e como seja grande a fome de imagens, destinada a crescer muito nos próximos anos, abrindo inimagináveis espaços a produtos (e subprodutos) que, de outro modo, permaneceriam segregados em seus mercados "provinciais".

Analisa as características estéticas, sociológicas, econômicas e acentua a diferenciação entre a telenovela em língua portuguesa, que dá importância ao look, à cenografia, aos pormenores técnicos, retomadas externas, siglas gráficas refinadas, e em espanhol, apoiando-se principalmente no pathos emotivo, descuidando pois, da ambientação e da cenografia, prevalecendo freqüentemente nas telenovelas mexicanas uma explícita empostação pedagógico-paternalista.

Quanto ao mercado, assinala a barreira lingüística como um dos problemas para a rápida colocação nos mercados internacionais, constituindo a dublagem um ulterior obstáculo à vendagem imediata de um programa, embora a preço baixo.

Explica as razões da maior vendagem dos produtos televisivos mexicanos: mais fácil colocação num mercado lingüístico mais amplo por ser a língua oficial da Espanha (38 milhōes de habitantes) e de 20 nações do centro e América 
do Sul (230 milhōes), além de ser corrente entre os filipinos (um milhão) e dos habitantes que não falam inglês dos EUA, cerca de 16 milhões, alcançando um total de cerca de 290 milhōes, enquanto que o português, além de Portugal (10 milhões) do Brasil, população não selvícola (130), Guiné-Bissau e Cabo Verde (1 milhão), Angola (9 milhões), Moçambique (12 milhões) perfaz um total de cerca de 160 milhōes de pessoas.

Apresenta estatísticas de importação de programas na América Latina nos principais países, indica a proveniência, em percentagem, dos programas importados, a distribuição por categorias em percentagem sobre o total transmitido: informativos, educativos, culturais, religiosos, diversão, esporte, tece comentários a respeito e indica que os países que adotaram a televisão antes da invenção dos videogravadores, quase todos os latinoamericanos, foram obrigados a produzir um certo número de programas ao vivo. Transcreve E. KATZ e G. WEDELL, Broadcasting in the third world, Cambridge, Harward Press, 1977, p. 73:

"O Brasil produziu todos os seus programas para os primeiros nove anos de televisão ao vivo, até ser introduzida a tecnologia do telecinema no país, em 1959 ... O primeiro Vtr foi introduzido em 1964",

mas contrapõe opiniões segundo as quais teria sido introduzido em 1962.

Indica que até então a Globo havia produzido cerca de 120 telenovelas, com uma média de 70 capítulos, implicando uma armazenagem de mais de oito mil horas de telenovelas, o que significaria transmitir durante um ano inteiro, 24 horas por dia, sem qualquer reprise.

As duas maiores "fábricas de telenovelas" do mundo são a Rede Globo e a Televisa Mexicana.

Desenvolve considerações a respeito de cada uma delas, mostrando que o custo de produção de uma novela gira em torno de 20 a 30 mil dólares para um produto "médio", enquanto que o custo de produção nos EUA de uma hora de Dallas custa entre 30 a 50 vezes mais: cerca de um milhão de dólares.

Aponta como outro protagonista do oligopólio produtor das telenovelas a Rede Bandeirantes de São Paulo, que também entrou firme na exportação, desembarcando naturalmente também na Itália.

Com base em P. FARINOTTI, I maghi del canale, Milão, Rizzoli, 1985, p. 122 mostra que foi certa sedução de Sonia Braga a vencer o ceticismo dos europeus em lançar as telenovelas. A primeira foi a Radiotelevisione da Suíça 
italiana (Risi) que dublou em italiano algumas telenovelas, depois adquiridas pela Retequattro:

\begin{abstract}
“O sucesso da primeira telenovela, Dancin' Days, foi impressionante. Constituiu uma pequena revolução do gosto, difundiu uma verdadeira febre que não poupou nenhuma, ou quase, mulher italiana... inserida às $14 \mathrm{~h} 00$, reinventou o período da tarde chamado cor-de-rosa e revelou uma nova, rica mina publicitária, tornando a Retequattro a líder da tarde",
\end{abstract}

fazendo com que a sua audiência alcançasse, às duas horas da tarde, três milhões de pessoas.

Escrava Isaura, retransmitida no mês de janeiro de 1982, alcançou o pico de 5 milhões, abrindo caminho a que as telenovelas alcançassem cada vez maiores espaços, passando de colocação "natural" para "tradicional".

Um acordo com a Retequattro permitiu-lhe, em 1982, exibir Ciranda de Pedra, Marisa, A Sucessora, e na estação 1983-1984 dobrar a exibição no horário entre $13 \mathrm{~h} 00$ e $15 \mathrm{~h} 00$, replicando Dancin'Days às $18 \mathrm{~h} 50-19 \mathrm{~h} 30$, determinando um hábito de audiência ao qual seguiu Sinhosinha Flô, Marrom Glacé, O Astro, Malu Mulher e Água Viva, alcançando com Os ricos também choram, em 1986, cerca de $10 \%$ da programação das redes comerciais italianas, que aumentou em 1986.

Existem na Itália três ou quatro sociedades de importação e de distribuição de telenovelas, além de vários operadores independentes. Até 1983 os clientes privilegiados eram naturalmente as redes, que hoje já compram por conta própria. A Telemontecarlo já nem mais tem necessidade de adquirir, por ser emanação da própria TV Globo, ao que deve ser atribuído o fato de, em 1985 , ter sido reduzido pela metade, com relação a 1984 o peso do Brasil nas estatísticas da importação. Os clientes, tornaram-se assim as emissoras locais independentes (ou pequenos circuitos), que pretendem uma exclusividade regional de pelo menos alguns meses, razão porque uma telenovela pode ser colocada no máximo em 20 estaçōes de televisão no país inteiro.

Até 1984 era justamente a Itália, com uma fome exasperada de imagens, que constituía uma das maiores fontes de lucro para a venda de telenovelas latinoamericanas, alcançando cada capítulo para uma rede local até 7.000 dólares, ao passo que Portugal for recia às telenovelas brasileiras proventos bem limitados: um capítulo não alcançava mais do que 500 dólares.

Pouco a pouco foi crescendo a demanda, como demonstram as vendas, ao exterior, da TV Globo, passando de 8 milhōes de dólares em 1982, para 12 ao

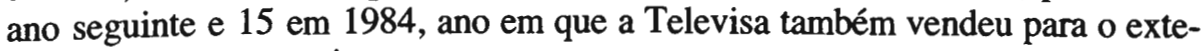
rior esta mesma quantia. 
Cresce cada vez mais o mercado em língua espanhola nos EUA: em 1985 havia 3.500.000 pessoas de fala espanhola em Los Angeles, $2.500 .000 \mathrm{em}$ Nova Iorque, um milhão em Miami, $800.000 \mathrm{em}$ San Antonio, $740.000 \mathrm{em}$ Chicago, 730.000 em San Francisco.

A TV Globo apóia-se todavia também no mercado norte-americano de língua inglesa depois de ter, em março de 1984, o Channel Four, da Grã-Bretanha, decidido adquirir A Escrava Isaura e dublá-la.

Com a Exposição Internacional de Produtos da TV de Cannes, em abril de 1984, as telenovelas iniciam a conquista da Europa: a Tf 1 compra da TV Globo Baila Comigo e o Canal Plus adquire A Escrava Isaura e Dancin'Days a 20.000 dólares o capítulo (dos quais 8.000 para a dublagem) telenovelas compradas também pela Alemanha e pelos Países Escandinavos.

A Escrava Isaura foi vendida também na China, dublada em quatro dialetos, tendo sido sua protagonista Lucélia Santos proclamada "atriz do ano" em Pequim. A China comprou também 65 capítulos de Dancin'Days e de outras três telenovelas num total de 500 horas. Telenovelas foram vendidas em 1985 também às televisões francesa, finlandesa, belga, suíça, polonesa, húngara $\mathrm{e}$ países africanos.

A TV Globo, que em 1972 não exportava quase nada, conseguiu vender, dez anos depois, também na Alemanha, e tenciona vender telenovelas para pelo menos 110 países no mundo inteiro.

Calcula Angelo Zaccone Teodosi o fluxo mundial de programas em cerca de 500.000 horas por ano, das quais $60-70 \%$ dos EUA e cerca de $10 \%$ da América Latina. Os Estados Unidos obtém da exportação de imagens de 600 a 700 milhões de dólares, e o Brasil e o México de 30 a 40, por enquanto!

Conclui demonstrando que a telenovela exemplifica a possibilidade de produzir televisão a baixo custo, mantendo-se ligada às próprias culturas nacionais, o que deveria servir de estímulo às sonolentas indústrias de televisão da Europa, que continua sujeitando-se à energia mítico-fabulatória de culturas que não são suas.

São Paulo, junho de 1988. 